\title{
SYNTHESIS AND CHARACTERIZATION OF COPPER NANOPARTICLES SUPPORTED IN CARBON NANOTUBES MULTIPLE WALLS PREPARED BY CLD AND SMAD
}

\author{
GALO CÁRDENAS-TRIVIÑO ${ }^{a^{*}}$ AND EVA SEPÚLVEDA-BUSTAMANTE ${ }^{b}$ \\ ${ }^{a}$ Facultad de Ingeniería, DIMAD, Escuela de Ingeniería Química, Universidad del Bío-Bío, Avda I. Collao 1202, Concepción, Chile. \\ ${ }^{b}$ Facultad de Ciencias Químicas, Universidad de Concepción, Edmundo Larenas 234, Concepción, Chile.
}

\begin{abstract}
The synthesis and characterization of copper nanoparticles supported in carbon nanotubes is reported. Copper nanoparticles were obtained by the CLD (chemical liquid deposition) method consisting of reduced pressure evaporation of metals and subsequent low-temperature condensation (77K) of these vapors, with organic solvent vapors. From the reactions obtained by this method, copper colloids of concentrations $10^{-3}$ and $10^{-4}$ were synthesized in the organic solvents 2-propanol, 2mercaptoethanol, 2-methoxyethanol and 2-ethoxyethanol. The support of copper nanoparticles in the carbon nanotubes was made by SMAD method with 24 hours under agitation and nitrogen atmosphere before collecting, obtaining copper nanoparticle solids supported in carbon nanotubes by evaporating the solvent either 2mercaptoethanol or 2-ethoxyethanol. Colloidal and solid dispersions were characterized by diverse techniques, for colloidal dispersions UV-Vis spectrophotometry, electrophoretic mobility, electron transmission microscopy (TEM), electron diffraction and stability over time was used. Far-medium infrared spectroscopy (FT-IR) and thermogravimetry (TGA) were used for solids. These analyses show that $\mathrm{Cu}$ colloids are relatively stable in the solvents used, the most stable dispersion was synthesized in 2-mercaptoethanol and the less stable is synthesized in 2-methoxyethanol, which is demonstrated in UV spectra. By TEM, particle sizes were studied, between 5.2 and $17.2 \mathrm{~nm}$. Electron diffraction confirms the presence of copper. Analysis of active solids shows in the case of FTIR that solvents are incorporated into copper particles, and in the case of thermograms it is shown that the solids synthesized in the solvent had greater thermal stability 2-mercaptoethanol. It was impossible to obtain electron diffraction from the copper nanoparticles visualized because they are incorporated in the multiwall nanotubes.
\end{abstract}

Keywords: Copper nanoparticles, carbon nanotubes, electron diffraction, transmission electron microscopy.

\section{INTRODUCTION}

The electrical conductivity of copper $\left(5.8 \times 10^{5} \mathrm{Scm}^{-1}\right)[1]$ and also the most thermal conductor among metals $\left(401 \mathrm{Wm}^{-1} \mathrm{~K}^{-1}\right.$ at $\left.27^{\circ} \mathrm{C}\right)$ [2]. Furthermore, copper has a high current carrying capacity [3]. Due to their electrical properties, copper is used in electrical power cables, generators motors and as a connectors in electronic devices. In electronics, copper interconnects disintegrate at high currents and delaminate from Si chips due to thermal expansion arising from heat built up [4]. An average middle size car contains about $22.5 \mathrm{~kg}$ of copper, while electric and hybrid cars contain higher level of copper [5]. Transition metals, especially precious metals, show great catalytic activity for many organic reactions. These materials have properties in both heterogeneous and homogeneous catalysis. Catalysis takes place at the active sites of metal cores [6].

Copper is paramagnetic, and with its ion states $\mathrm{Cu}^{+}$and $\mathrm{Cu}^{2+}$ presents catalytic activity, easy of forming paramagnetic compounds and tendency to form complex ions. It is moderately hard, tenacious in extreme and wear-resistant; the most used metal to manufacture electrical cables apart from other electrical and electronic components, a leading export product in our country. These and other properties make it an attractive research material.

Carbon nanotubes are carbon structures belonging to the group of fullerenes. They consist of one or more layers of graphite rolled on itself, depending on this are called multilayers or monolayer.

They are extremely resistant to mechanical stress, being the most resistant material known to date, highly flexible and have semiconductor properties, metallic or sometimes superconducting, that is how carbon nanotubes are the ideal material for nanostructures for their strength and conductivity.

Colloidal solutions in particular have properties that are typical and characteristic to it, such as kinetic, optical and electrical properties. In this case, copper in colloidal suspension was studied in organic solvents. The advantage of the organic medium is that stabilized ligating nanoclusters can be formed with behaviors of great research interest [7].

Metallic colloids are one of the kinds of nanoscale materials that have been extensively studied, although these metallic nanoparticles are unstable with respect to the physical state, have the advantage of having the appropriate size and well-defined characteristics. This co-deposition reaction or chemical liquid deposition (CLD) method is carried out in a static reactor cooled to the temperature of liquid nitrogen, which favors condensation and formation of a metal-organic matrix. Defrosting the metal-organic matrix results in the process of nucleation and growth of nanoscale particles $-196^{\circ} \mathrm{C}$ [8].

$\mathrm{Cu} / \mathrm{CNT}$ to replace copper in real life applications. Literature reports indicates that $\mathrm{Cu} / \mathrm{CNT}$ performances (electrical, thermal and mechanical) reported so far rival that of $\mathrm{Cu}$, proving the materials viability as a $\mathrm{Cu}$ alternative. The current best $\mathrm{Cu} / \mathrm{CNT}$ performances already qualify for application in niche electronic device markets as high-end interconnects.

However, $\mathrm{Cu} / \mathrm{CNT}$ application as copper replacements in conventional electronics and in electrical/data wires are long-term goals, needing inexpensive mass-production by methods aligned with existing industrial practices. Sustained research on $\mathrm{Cu} / \mathrm{CNT}$ it is expected the successful evolution of highly functional, efficient, and sustainable next-generation electrical and electronics devices.

$\mathrm{Cu}$ with carbon nanotubes (CNT) composites are ready to achieve the growing need for $\mathrm{Cu}$ substitutes [9]. CNTs are expected to play two roles in $\mathrm{Cu} / \mathrm{CNT}$. i) The CNTs is a weight reducer, producing the composites lighter. CNTs could transmit their outstanding nanoscale variety of properties to $\mathrm{Cu}$ to yield composites with superior properties. In fact, $\mathrm{CNT}$ addition to $\mathrm{Cu}$ is reported to increase mechanical, electrical and thermal properties [9 - 18] showing the future of $\mathrm{Cu} / \mathrm{CNT}$. ii) Then, Arnaud et al. [19] report $1.5 \mathrm{~m}$ long $\mathrm{Cu} / \mathrm{CNT}$ wires made by powder processing with diameters similar to industrial copper wires $(0.2-1.0$ $\mathrm{mm})$. The $\mathrm{Cu} / \mathrm{DWCNT}(0.5 \mathrm{vol} . \%)$ wires were produced by ultrasonication mixing, followed by SPS and wire drawing and showed tensile strengths greater than $\mathrm{Cu}$ and room temperature electrical conductivities similar to $\mathrm{Cu}$.

\section{EXPERIMENTAL}

\subsection{Synthesis of metal colloids}

Cu's colloids were prepared using the method called Chemical Liquid Deposition (CLD), which consists of physical co-deposit to $77 \mathrm{~K}$ of metal vapors $(\mathrm{Cu})$ with organic vapors (2-propanol, 2-ethoxyethanol, 2-mercaptoethanol and 2-methoxyethanol, Sigma) in a metal atoms reactor.

The solvent is placed in a degassing flask, then attached to the vacuum line; the vacuum is expected to be reached $\left(10^{-4}\right.$ torr) and the solvent is frozen with $\mathrm{N}_{2(1)}$; once frozen it is allowed to thaw slowly, during this process the gas bubbles are formed which are removed by vacuum, when the solvent is completely defrosted, the freezing-thawing cycle is repeated until no gas emission is observed.

For concentration $10^{-3} \mathrm{M}, 6.4 \times 10^{-3} \mathrm{~g}$ are massed and for concentration $10^{-4} \mathrm{M}$, $6.4 \times 10^{-4} \mathrm{~g}$ of copper in blasts in the crucible and then connected to the lower ends of the electrodes. The glass reactor is joined to the head by vacuum and is expected to reach a low vacuum or equal to $0.05 \mathrm{~atm}$; at this stage the degasifier flask has already been connected to one of the outputs with the solvent.

Once the required vacuum is reached, the Dewar with $\mathrm{N}_{2(1)}$ is placed, maintaining a temperature of $77 \mathrm{~K}$. About $5 \mathrm{ml}$ of solvent is allowed to evaporate to form a layer of solvent on the walls to prevent the metal from sticking to the 
reactor walls. It's increased the amperage of both crucibles slowly until both metals begin to evaporate simultaneously in conjunction with the cocondensation of the solvent. It is important to reach the end of the reaction with an excess solvent, i.e. the metals must evaporate completely a little before passing all the solvent.

When the solvent and metals have evaporated, $\mathrm{N}_{2(1)}$ is removed by keeping the reactor inside the Dewar for 1 hour. The Dewar is then removed and purged with $\mathrm{N}_{2}$ (g) for 45 more minutes. After completing the above times, the colloid obtained, by means of a siphon from the bottom of the reactor, is subtracted in an environment of $\mathrm{N}_{2}(\mathrm{~g})$. [20,21].

\subsection{Preparation of copper nanoparticles supported in carbon nanotubes}

Previously has been briefly explained, the method used to obtain carbon nanotubes-copper nanoparticles is a variant of the CLD method used for nanoparticles, called the SMAD method.

The same amounts of copper mentioned in the previous point are massed, but add $0.0500 \mathrm{~g}$ or $0.0250 \mathrm{~g}$ of multiwall nanotubes (Sigma) to the bottom of the reactor are placed with a magnetic bar. The same procedure described above is followed, with the difference being that 24 hours of resting before collecting, under permanent agitation and an atmosphere of $\mathrm{N}_{2}(\mathrm{~g})$.

\subsection{Obtaining the powdered carbon copper-nanotube material}

The drying of the material obtained is performed by direct evaporation of the solvent from the colloidal dispersions supported in carbon nanotubes. To achieve this, the receiving flask is connected to the vacuum line for a period of approximately two hours, and more than one day in some cases. Once the solvent is evaporated, the flask is removed and solid collected and stored in a dry chamber under the nitrogen gas to prevent oxidation of the material [22].

\subsection{Characterization of colloids and solids}

Both the metal colloids, colloidal suspensions of carbon copper nanoparticles and carbon solids were characterized by various techniques. The colloidal suspensions were characterized by UV-Vis spectrophotometry, electrophoretic mobility, TEM and electron diffraction. Copper nanoparticle colloids in addition to the above were also given a time stability study, which consisted of observing suspended particles over the days. The powdered material obtained from the copper nanoparticle supported on carbon nanotubes was tested using the FT-IR and TGA techniques.

\subsection{Characterization of colloidal suspensions}

\subsubsection{Kinetic stability}

The stability for each of the colloidal dispersions is studied through the physical and chemical behavior of these in time at room temperature, by direct observation.

\subsubsection{Electronic Transmission Microscopy (TEM)}

The particle size of colloidal dispersions was estimated by frequency histogram of particle sizes obtained by electron microscopy (TEM) under the JEOL JEM 1200 EX II transmission microscope at 4x resolution. It is taken with a Hamilton $1 \mu \mathrm{L}$ syringe of colloidal suspension (diluted 10 times) and deposited on a 150 mesh nickel grid under an inert environment. The "Digital micrograph" computational program is used for interpretation of results, measuring 50 particles per image. With this data, the frequency histogram is performed.

\subsubsection{Electron diffraction}

The diffraction patterns of the particles were taken from the microscope JEOL JEM 1200 EX II operating under the conditions of 120kV; $60 \mathrm{~cm}$; K: $4.209(\mathrm{~cm})$ was used to identify possible phases present in the dispersion.

\subsubsection{UV-Vis spectrophotometry}

Absorption spectra were recorded between 200 and $500 \mathrm{~nm}$ using Schimadzu UV 2450 equipment. To take the spectra were used 2 quartz buckets optical path b: $1 \mathrm{~cm}$, volume: $1 \mathrm{~mL}$. An aliquot of $1 \mathrm{~L}$ of diluted colloid is taken with $1 \mathrm{~mL}$ of the solvent used in it, and a blank of the same solvent. Results were recorded under environmental conditions, the first 5 days were measured every 24 hours, from time 0 to $120 \mathrm{~h}$, then distanced according to visual changes of the saved suspension.

\subsubsection{Electrophoretic mobility}

Electrophoretic studies were done on the "Zeta Meter System 3.0" equipment. For this purpose a quartz cell is used, which is washed with distilled water and washed with the organic solvent of the suspension to be measured.

Following this, the colloid cell is filled, making sure there are no bubbles left. The platinum and molybdenum electrodes are then adjusted to the cell, connected to the power source of the equipment, causing an electric field in the suspension. It is adjusted to the point of electrophoretic mobility in the particles, towards one of the electrodes, (if they move to the left they are attracted to the positive molybdenum electrode, and to the platinum electrode if they are of opposite charge).

The value of electrophoretic mobility is delivered directly by the equipment, under an average of 50 measures. While an important factor in suspensions of nanoparticles are the forces of potential in the outer layer that interacts with the solvent, joining and creating forces of repulsion or attraction between particles. This is called zeta potential, and is calculated under the equation of Smoluchowsky $[8,23]$ :

$$
\xi=\frac{113 x \eta}{D} x \mu_{e}
$$

Where:

$\xi$ : zeta potential $(\mathrm{mV})$

$\mu_{\mathrm{e}:}$ Electrophoretic mobility (microns $/$ second s volt $/ \mathrm{cm}$ )

$\eta$ : suspension viscosity (poise)

D: solvent dielectric constant

Measurements were carried out every 24 hours for the first 5 days (from time 0 to $120 \mathrm{~h}$ ). For the calculation of mobility, the average mobility was used for each solvent [23]. The viscosities of the solvents were experimentally calculated at working temperature with a $5 \mathrm{~mL}$ Ostwald viscometer and thermostatic bath, using the supernatant colloid.

\subsection{Characterization of copper nanoparticles supported in carbon nanotubes.}

\subsubsection{Elemental analysis by atomic absorption spectrophotometry}

The analysis performed by spectrophotometry was performed on the Thermo Scientific ICE 3000 series AA, with a calibration curve of $0.05 \mathrm{ppm}$ at $2 \mathrm{ppm}$ copper. The sample was treated for acid digestion with $\mathrm{HNO}_{3}$ (conc).

\subsubsection{Fourier Transform Infrared Spectroscopy (FT-IR)}

The infrared spectra of the solids were obtained by preparing $\mathrm{KBr}$ pellets with 128 scans on the Nicolet Magna 550 equipment. The FT-IR spectra of the solvents were obtained by depositing a drop of the solvent on a pure $\mathrm{KBr}$ solid previous to prepare the disk.

\subsubsection{Thermogravimetric Analysis (TGA)}

Thermogravimetry analysis was done on the (TGA) TA instruments Q50 equipment. Between 3 and $5 \mathrm{mg}$ sample were used and the temperature was increased from $500^{\circ} \mathrm{C}$ with a heating rate of $10^{\circ} \mathrm{C} / \mathrm{min}$ with flow of $\mathrm{N}_{2}(\mathrm{~g})$ of 50 $\mathrm{mL} / \mathrm{min}$.

\subsubsection{Electronic transmission microscopy}

Studies conducted by transmission electron microscopy (TEM) in particle size determination were conducted under a JEOL JEM 1200EXII microscope with 4x resolution. A drop of the nanoparticles supported in diluted carbon nanotubes was deposited 10 times, on a 150 mesh Ni grid provided in the same way as the colloids. 


\section{RESULTS AND DISCUSSION}

The following reaction summarizes the colloidal synthesis as shown in Figure 1:

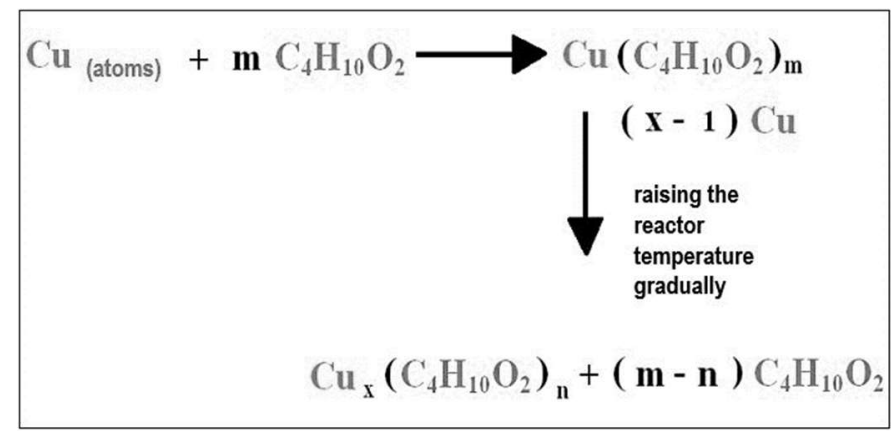

Figure 1. Synthesis reaction scheme

\subsection{Stability of colloidal dispersions.}

Colloidal dispersions are thermodynamically unstable systems, therefore easily modifiable and inducible to flocculation. If the size distribution is very wide it forms unstable systems, as well as by chemical modification of the particle surface over time [24]. Table 1 summarizes the stability of copper dispersions in 2-methoxyethanol, 2-ethoxyethanol, 2-propanol and 2mercaptoethanol, resulting in the most unstable with 2-mercaptoethanol. When flocculated, a separation between the solvent and the metallic particles flocculated at the bottom is observed.

In the case of 2-methoxyethanol it is observed that it flocculates gradually, in the case of 2-ethoxyethanol and 2-propanol the change was observed more suddenly. For 2-mercaptoethanol, being the dispersion less stable, it is seen that it coagulates but does not decant, but more agglomerations are observed suspended and few in the background, thus staying for quite some time (more than 30 days).

Table 1. Stability of colloids manufactured in different solvents at concentrations $10^{-3}$ and $10^{-4} \mathrm{M}$.

\begin{tabular}{|c|c|c|c|c|}
\hline Solvent & $\begin{array}{c}\text { Copper } \\
\text { Concentration } \\
\text { (M) }\end{array}$ & $\begin{array}{c}\text { Stability } \\
* \text { (days) }\end{array}$ & $\begin{array}{c}\text { Colloid } \\
\text { color } \\
\text { (initial) }\end{array}$ & $\begin{array}{c}\text { Colloid } \\
\text { color } \\
\text { (final) }\end{array}$ \\
\hline 2-methoxyethanol & $10^{-3}$ & $<30$ days & light brown & dark brown \\
\hline 2-methoxyethanol & $10^{-4}$ & $<30$ days & light brown & dark brown \\
\hline 2-ethoxyethanol & $10^{-3}$ & $<60$ days & transparent & dark brown \\
\hline 2-ethoxyethanol & $10^{-4}$ & $>30$ days & transparent & yellowish \\
\hline 2-propanol & $10^{-3}$ & $<30$ days & light brown & $\begin{array}{c}\text { light } \\
\text { brown }\end{array}$ \\
\hline 2 -propanol & $10^{-4}$ & $<60$ days & light brown & $\begin{array}{c}\text { light } \\
\text { brown }\end{array}$ \\
\hline 2-mercaptoethanol & $10^{-3}$ & $>120$ days & transparent & $\begin{array}{c}\text { light } \\
\text { brown pink }\end{array}$ \\
\hline 2-mercaptoethanol & $10^{-4}$ & $>120$ days & transparent & $\begin{array}{c}\text { light } \\
\text { brown pink }\end{array}$ \\
\hline
\end{tabular}

*qualitative observation.

The kinetic stability of colloidal dispersions depends on two main factors: i) Coalescence between particles due to the clustering during the Brownian movement of these, which forms large aggregates.

ii) By chemical modification of its surface due to contact with reactive atmospheres or the addition of certain chemical species.

The higher the dielectric constant the solvent molecules will be solvated strongly to copper nanoparticles. In this case it is fulfilled that the dispersion in 2-mercaptoethanol is the most stable, having a dielectric constant almost 3 times greater than that followed by the solvents used (See table 1). When it comes to colors, as we approach the visible range the colloidal particles are larger, the most colored dispersions turn out to be those of 2-methoxyethanol (brown), and those of 2-mercaptoethanol, which are pink, but after 4 months.

\subsection{Electronic transmission microscopy}

Particle sizes were obtained through the analysis of micrographs obtained under the JEOL JEM 1200 EXII electron microscope with $4 \mathrm{x}$ resolution to a specific particle population. This type of area was revised using the dark field technique as well as by light field, as shown in figures 2 to 6. Optical measurements of randomly chosen particle population diameters were represented in a histogram, Gaussian curves and standard deviations were also adjusted.

In the case of 2-ethoxyethanol and concentration $10^{-4} \mathrm{M}$ of 2-propanol it is not possible to determine the size. Assuming the images are nanoparticles less than $8 \mathrm{~nm}$ (which is very likely) the cause of blurred and almost zero vision of the image is the low resolution of the equipment used.

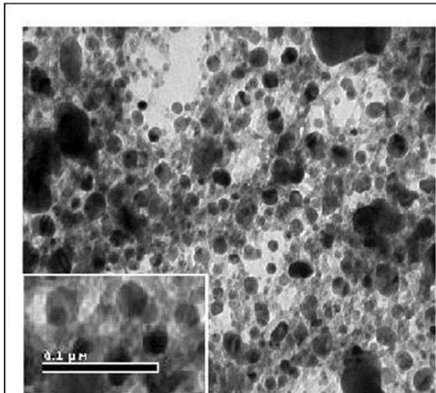

(a)

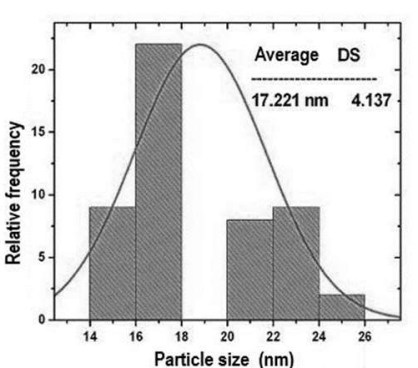

(b)
Figure 2. (a) Electronic transmission micrograph (TEM) of copper nanoparticles for 2-methoxyethanol $\left(10^{-3} \mathrm{M}\right)$; (b) Frequency histogram of particle sizes in $\mathrm{nm}$.

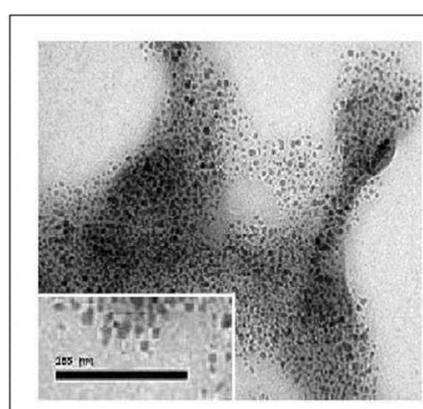

(a)

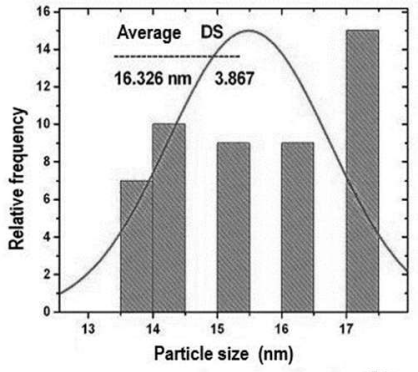

(b)
Figure 3. (a) Electronic transmission micrograph (TEM) of copper nanoparticles for 2-methoxyethanol $\left(10^{-4} \mathrm{M}\right)$; (b) Frequency histogram of particle sizes in $\mathrm{nm}$ for 2-methoxyethanol.

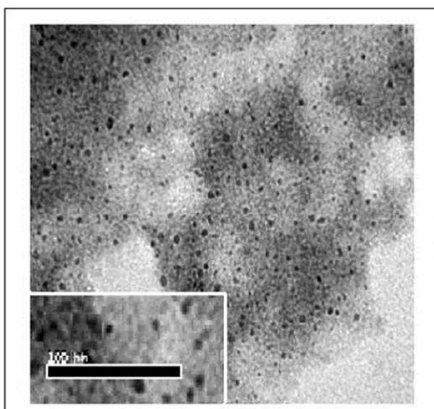

(a)

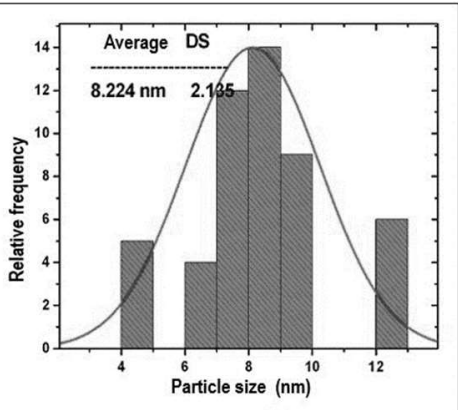

(b)
Figure 4. (a) Electronic transmission micrograph (TEM) of copper nanoparticles for 2-propanol $\left(10^{-3} \mathrm{M}\right)$; (b) Frequency histogram of particle sizes in $\mathrm{nm}$. 


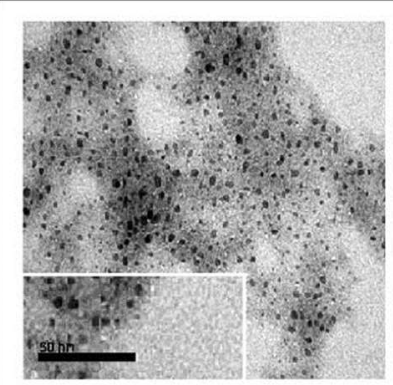

(a)

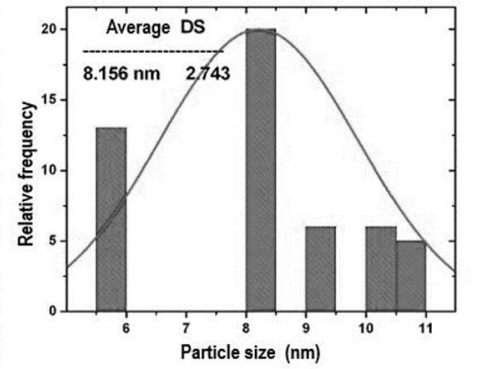

(b)
Figure 5. (a) Electronic transmission micrograph (TEM) of copper nanoparticles for 2-mercaptoethanol $\left(10^{-3} \mathrm{M}\right)$; (b) Frequency histogram of particle sizes in $\mathrm{nm}$.

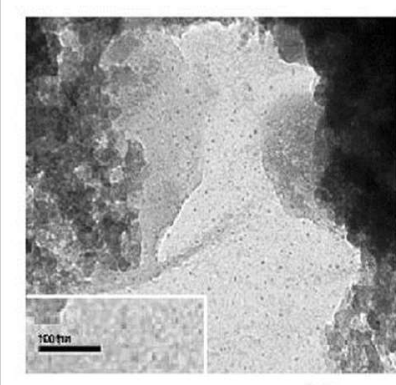

(a)

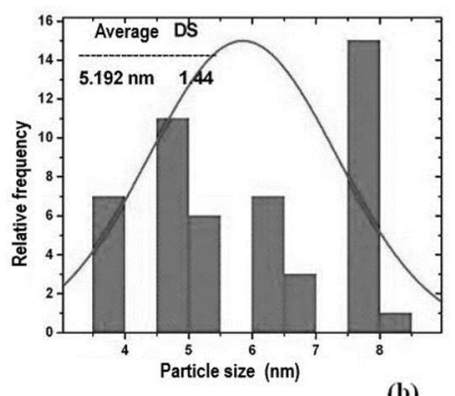

(b)
Figure 6. (a) Electronic transmission micrograph (TEM) of copper nanoparticles for 2-mercaptoethanol $\left(10^{-4} \mathrm{M}\right)$; (b) Frequency histogram of particle sizes in $\mathrm{nm}$.

From the results we can say that, as in the work carried out by Cárdenas and Oliva [26] the copper particles of greater size and largest dispersion in size are those synthesized in 2-methoxyethanol. The smallest and least dispersed are those synthesized in 2-mercaptoethanol. The 2-propanol solvent is at an intermediate level. It was not possible to analyze the suspensions in 2ethoxyethanol due to the unclear image of the particles. Table 2 summarizes the particle sizes.

Table 2. Copper particle sizes for different solvents and concentrations.

\begin{tabular}{|c|c|c|c|}
\hline Solvent & Concentration (M) & Particle size (nm) & SD (nm) \\
\hline 2-methoxyethanol & $10^{-3}$ & 17.2 & 4.1 \\
\hline 2-methoxyethanol & $10^{-4}$ & 16.3 & 3.8 \\
\hline 2-ethoxyethanol & $10^{-3}$ & $----^{*}$ & $---{ }^{*}$ \\
\hline 2-ethoxyethanol & $10^{-4}$ & $----^{*}$ & $---*^{*}$ \\
\hline 2-propanol & $10^{-3}$ & 8.2 & 2.1 \\
\hline 2-propanol & $10^{-4}$ & ---- & $---{ }^{*}$ \\
\hline 2-mercaptoethanol & $10^{-3}$ & 8.1 & 2.7 \\
\hline 2-mercaptoethanol & $10^{-4}$ & 5.1 & 1.4 \\
\hline
\end{tabular}

*It was not possible to determine the particle size due to the low resolution of the equipment and agglomeration of the colloids in the microscope grid.

\subsection{Electron diffraction}

From the studies carried out in TEM, apart from the size of the particles, electron diffraction analyses were carried out, the one that delivers the information of the crystalline structure of the samples, comparing crystallographic constants corresponding to the crystalline structure of the copper with those of the sample, we corroborate whether the nanoparticles are made of copper, copper oxide or some other molecule formed between copper and solvent. Shown here are the electron diffraction images for each solvent, captured by the JEOL JEM 1200 EXII electron microscope with $120 \mathrm{kV}$, also shown in the table the experimental crystallographic planes and theoretical values.

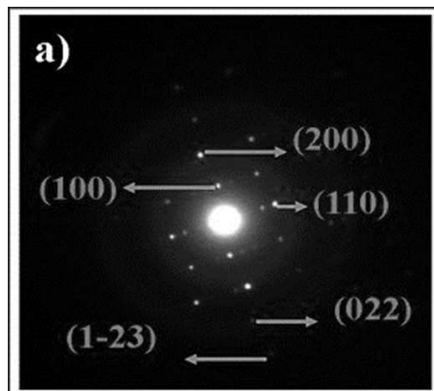

b)

Network parameters:

$\mathrm{a}=3.6$

$b=3.6$

$c=3.6$

$\alpha=\beta=y=90^{\circ}$

$\mathrm{Cu}$ (FCC)

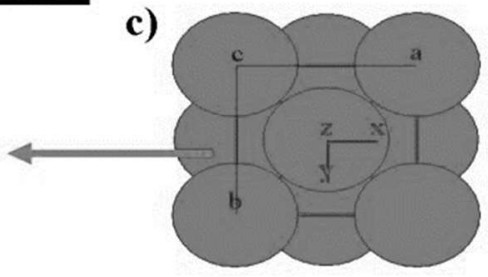

Figure 7. a) Electron diffraction pattern for $\mathrm{Cu}$-2-ethoxyethanol nanoparticles obtained with a concentration of $1 \times 10^{-4} \mathrm{~mol} / \mathrm{L}: \mathrm{b}$ ) Expansion of the crystalline network of $\mathrm{Cu}$ (FCC) in the three directions $\mathrm{x}, \mathrm{y}, \mathrm{z}$; c) Crystal Structure of the $\mathrm{Cu}$ (FCC) and network parameters of $\mathrm{Cu}$ nanoparticles obtained by CLD.

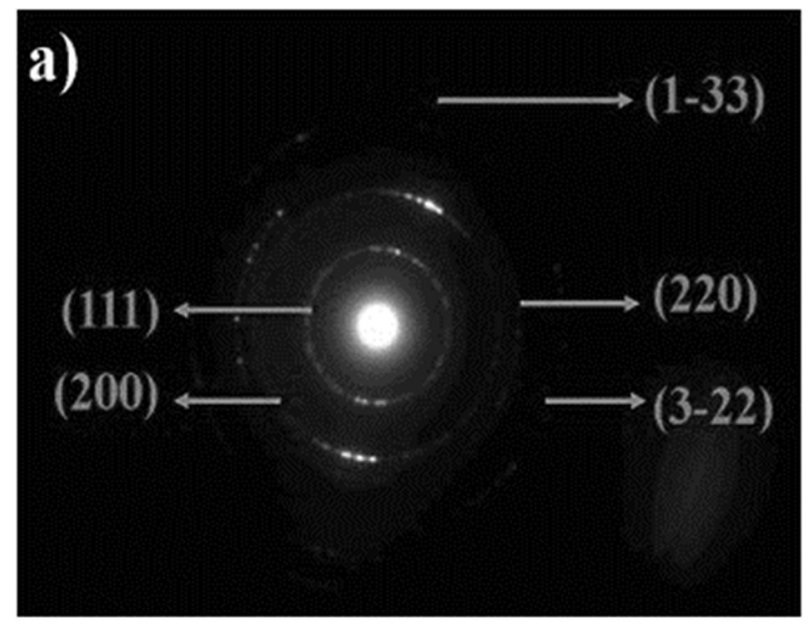

Figure 8. a) Electron diffraction pattern for $\mathrm{Cu}$-2-propanol nanoparticles obtained with a concentration of $1 \times 10^{-3} \mathrm{~mol} / \mathrm{L}$.

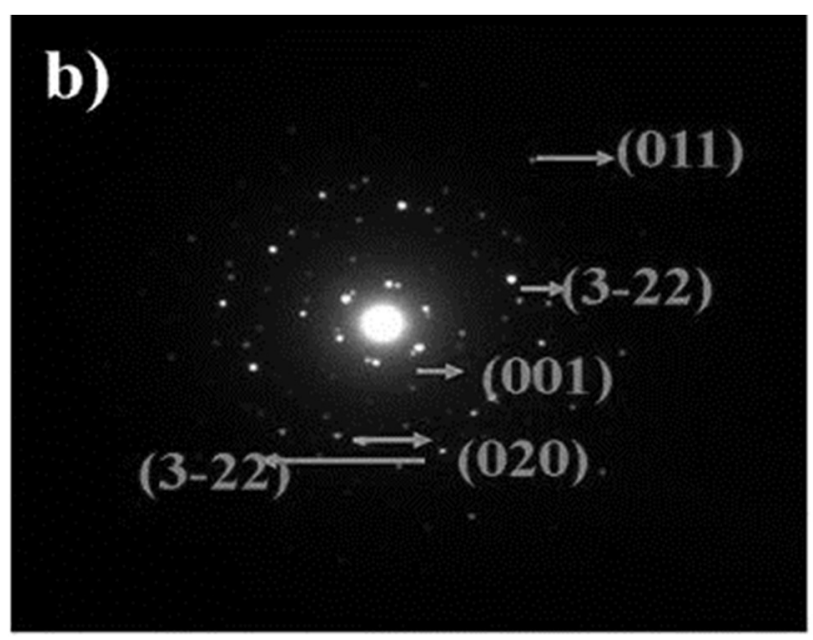

Figure 9. b) Electron diffraction pattern for $\mathrm{Cu}$-2-mercaptoethanol nanoparticles obtained with a concentration of $1 \times 10^{-4} \mathrm{~mol} / \mathrm{L}$. 


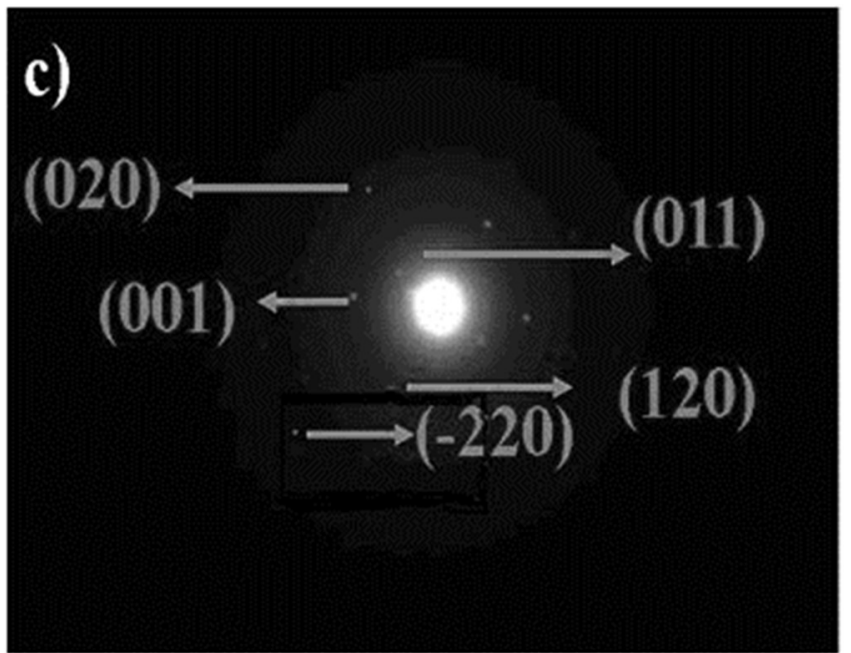

Figure 10. c) Electron diffraction pattern for $\mathrm{Cu}$-2-methoxyethanol nanoparticles obtained with a concentration of $1 \times 10^{-4} \mathrm{~mol} / \mathrm{L}$.

Table 3. Theoretical and experimental values for crystallographic planes, together with them the relative error resulting from the measurements.

\begin{tabular}{|c|c|c|c|c|}
\hline \multirow{2}{*}{ Cu-Solvent } & $d_{\text {hkl } \AA}$ & Phase & $d_{\text {hkl } \AA}$ & \multirow{2}{*}{ Error (\%) } \\
\hline & (exp) & Assigned & $\left(\operatorname{Ref}^{*}\right)$ & \\
\hline \multirow{5}{*}{$\mathrm{Cu}$-2-methoxyethanol } & 3.57 & $\mathrm{Cu}_{(\mathrm{fcc})}(001)$ & 3.61 & 1.1 \\
\hline & 2.56 & $\mathrm{Cu}_{(\mathrm{fcc})}(011)$ & 2.55 & 0.4 \\
\hline & 1.81 & $\mathrm{Cu}_{(\mathrm{fcc})}(020)$ & 1.80 & 0.5 \\
\hline & 1.61 & $\mathrm{Cu}_{\text {(fcc) }}(120)$ & 1.61 & 0.0 \\
\hline & 1.28 & $\mathrm{Cu}_{\text {(fcc) }}(-220)$ & 1.27 & 0.8 \\
\hline \multirow{5}{*}{$\mathrm{Cu}$-2-ethoxyethanol } & 3.37 & $\mathrm{Cu}_{(\mathrm{fcc})}(100)$ & 3.61 & 6.6 \\
\hline & 2.56 & $\mathrm{Cu}_{(\mathrm{fcc})}(110)$ & 2.55 & 0.4 \\
\hline & 1.75 & $\mathrm{Cu}_{(\mathrm{fcc})}(200)$ & 1.80 & 2.7 \\
\hline & 1.17 & $\mathrm{Cu}_{(\mathrm{fcc})}(022)$ & 1.27 & 7.8 \\
\hline & 0.90 & $\mathrm{Cu}_{\text {(fcc) }}(1-23)$ & 0.96 & 6.2 \\
\hline \multirow{5}{*}{$\begin{array}{c}\mathrm{Cu}-2- \\
\text { mercaptoethanol }\end{array}$} & 3.54 & $\mathrm{Cu}_{(\mathrm{fcc})}(001)$ & 3.61 & 1.9 \\
\hline & 2.48 & $\mathrm{Cu}_{(\mathrm{fcc})}(011)$ & 2.55 & 2.7 \\
\hline & 1.81 & $\mathrm{Cu}_{(\mathrm{fcc})}(020)$ & 1.80 & 0.5 \\
\hline & 0.88 & $\mathrm{Cu}_{\text {(ffc) }}(3-22)$ & 0.87 & 1.1 \\
\hline & 0.63 & $\mathrm{Cu}_{\text {(fcc) }}(3-33)$ & 0.69 & 8.6 \\
\hline \multirow{5}{*}{$\mathrm{Cu}$-2-propanol } & 2.08 & $\mathrm{Cu}_{(\mathrm{fcc})}(022)$ & 2.27 & 8.3 \\
\hline & 1.80 & $\mathrm{Cu}_{\text {(ffc) }}(1-23)$ & 1.77 & 1.7 \\
\hline & 1.20 & $\mathrm{Cu}_{(\mathrm{fcc})}(200)$ & 1.18 & 2.2 \\
\hline & 0.87 & $\mathrm{Cu}_{\text {(fcc) }}(022)$ & 0.89 & 2.2 \\
\hline & 0.82 & $\mathrm{Cu}_{(\mathrm{fcc})}(1-23)$ & 0.81 & 1.2 \\
\hline
\end{tabular}

\subsection{UV-Vis spectroscopy.}

Spectroscopic measurements performed on colloidal dispersions at concentration $10^{-4} \mathrm{M}$ resulted in absorption bands at $206 \mathrm{~nm}$, which coincide with the theoretical values calculated by Creigthon and collaborators [24].The results are shown in figures 11,12 and 13.

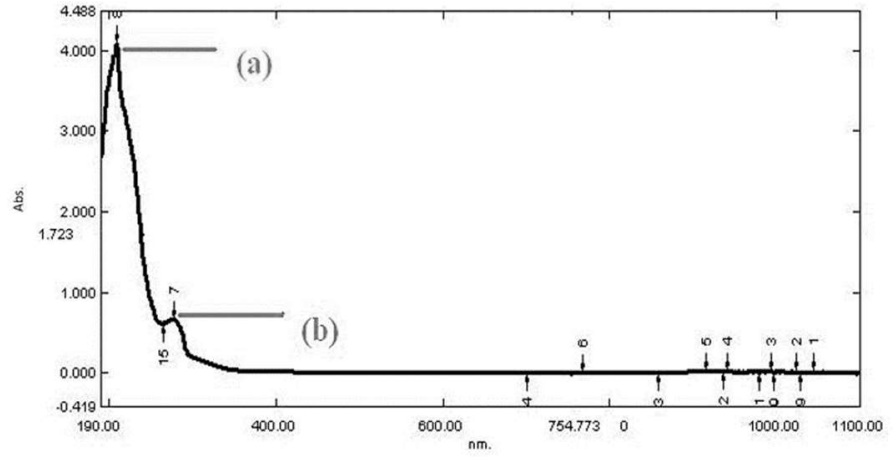

Figure 11. UV spectrograms for colloidal suspension $10^{-4}$ in solvent 2methoxyethanol measured in time (a) At the time of obtaining; (b) At 48 hours synthesized.

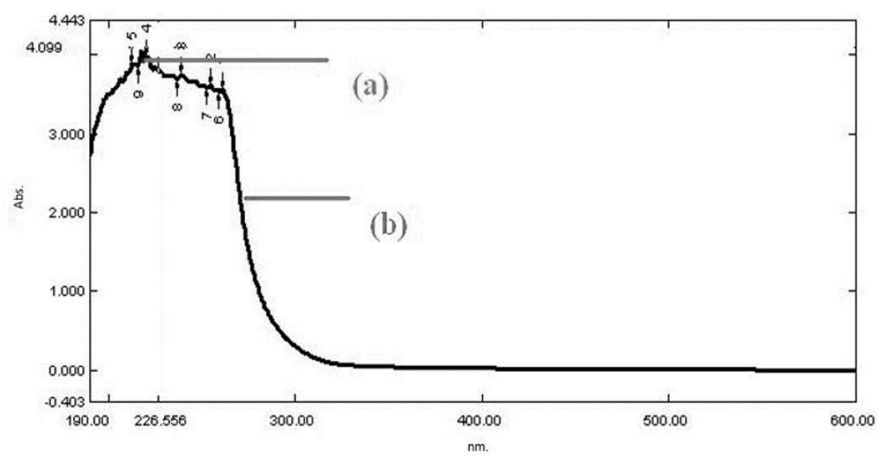

Figure 12. U.V spectrograms for colloidal suspension $10^{-4}$ in solvent $2-$ propanol measured in time (a) At the time of obtaining; (b) at 48 hours of synthesized.

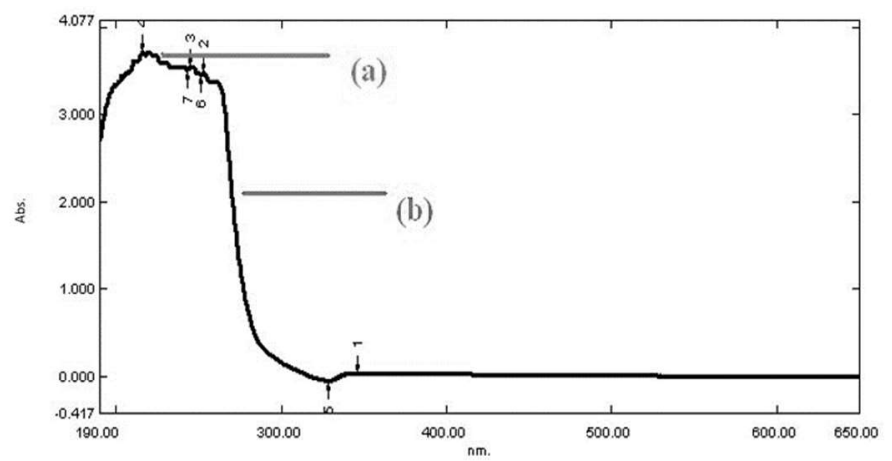

Figure 13. UV spectrograms for colloidal suspension $10^{-4}$ in solvent 2ethoxyethanol measured over time (a) At the time of obtaining; (b) At 48 hours of synthesized.

Creigthon's calculations were carried out with spherical particles with diameters of $10 \mathrm{~nm}$, which is in the order of measurement of the nanoparticles performed in this work. A spectroscopic study was conducted over time, reading the sample at the time of collection and at 48 hours. In this time range you can see the displacement to the visible of the characteristic peak to copper as colloidal dispersion, this is explained to the agglomeration and decanting of the nanoparticles, remaining less and less in suspension. Peak widening is also appreciated, this can be explained by the progressive increase in particle size which makes a greater size distribution, being observed more accentuated in 2propanol.

\subsection{Electrophoresis}

The measures of electrophoretic mobility and charge of copper colloids were performed on all solvents used (2-mercaptoethanol, 2-methoxyethanol, 2ethoxyethanol, 2-propanol). The Smoluchosky equation was used to determine the zeta potential of the particles. 
The bibliographic data are shown in Table 4, the results are shown in Table 5 and 6 where $(\eta)$ viscosity, electrophoretic mobility and $(\xi)$ zeta potential.

Table 4. Electrokinetic properties of colloidal copper suspensions $10^{-4} \mathrm{M}$.

\begin{tabular}{|c|c|c|c|}
\hline Solvent & $\begin{array}{c}\text { Dielectric constant } \\
\mathbf{2 5}^{\mathbf{}} \mathbf{C}\end{array}$ & $\begin{array}{c}\boldsymbol{\eta} \text { (poise) } \mathbf{x 1 0} \\
\mathbf{2 5} \mathbf{C}\end{array}$ & Charge \\
\hline 2-mercaptoethanol & 47.2 & 2.58 & Negative \\
\hline 2-methoxyethanol & 16.9 & 1.26 & Negative \\
\hline 2-ethoxyethanol & 29.6 & 1.83 & Negative \\
\hline 2-propanol & 18.3 & 2.08 & Positive \\
\hline
\end{tabular}

Table 5. Electrophoretic mobility of copper suspensions $10^{-4} \mathrm{M}$ over time.

\begin{tabular}{|c|c|c|c|c|c|}
\hline Solvent & $\begin{array}{c}\mu_{\mathrm{e}} \mathbf{0 ~ h} \\
(\mathrm{micr} / \mathrm{s} \mathrm{x} \\
\mathrm{V} / \mathrm{cm})\end{array}$ & $\begin{array}{c}\mu_{\mathrm{e}} 24 \mathrm{~h} \\
(\mathrm{micr} / \mathrm{s} \mathrm{x} \\
\mathrm{V} / \mathrm{cm})\end{array}$ & $\begin{array}{c}\mu_{\mathrm{e}} 48 \mathrm{~h} \\
(\mathrm{micr} / \mathrm{s} \mathrm{x} \\
\mathrm{V} / \mathrm{cm})\end{array}$ & $\begin{array}{c}\mu_{\mathrm{e}} 72 \mathrm{~h} \\
(\mathrm{micr} / \mathrm{s} \mathrm{x} \\
\mathrm{V} / \mathrm{cm})\end{array}$ & $\begin{array}{c}\mu_{\mathrm{e}} 96 \mathrm{~h} \\
(\mathrm{micr} / \mathrm{s} \mathrm{x} \\
\mathrm{V} / \mathrm{cm})\end{array}$ \\
\hline 2-mercaptoethanol & 96.7 & 5.6 & 3.9 & 10.1 & ---------* \\
\hline 2-methoxyethanol & 7.3 & 59.2 & 101.9 & 98.8 & 73.6 \\
\hline 2-ethoxyethanol & 58.1 & 59.7 & 87.4 & 67.8 & 110.4 \\
\hline 2-propanol & 0.3 & 0.5 & 2.3 & 2.9 & 2.2 \\
\hline
\end{tabular}

Table 6. Potential zeta of colloidal copper suspensions $10^{-4} \mathrm{M}$ in time.

\begin{tabular}{|c|c|c|c|c|c|}
\hline Solvent & $\begin{array}{c}\xi(\mathbf{m V}) \\
\mathbf{0 h r s}\end{array}$ & $\begin{array}{c}\boldsymbol{\xi}(\mathbf{m V}) \\
\mathbf{2 4 h}\end{array}$ & $\begin{array}{c}\boldsymbol{\xi}(\mathbf{m V}) \\
\mathbf{4 8 h}\end{array}$ & $\begin{array}{c}\boldsymbol{\xi}(\mathbf{m V}) \\
\mathbf{7 2 h}\end{array}$ & $\begin{array}{c}\boldsymbol{\xi}(\mathbf{m V}) \\
\mathbf{9 6 h}\end{array}$ \\
\hline 2-mercaptoethanol & 5.97 & 0.34 & 0.24 & 0.62 & $-------*$ \\
\hline 2-methoxyethanol & 0.61 & 4.98 & 8.58 & 8.32 & 6.20 \\
\hline 2-ethoxyethanol & 4.16 & 4.10 & 6.10 & 4.73 & 7.70 \\
\hline 2-propanol & 0.03 & 0.06 & 0.29 & 0.37 & 0.28 \\
\hline
\end{tabular}

The trend of variations in the zeta potential is due to the constant flocculation of particles in time at room temperature in the case of 2-propanol. Therefore, although the dielectric constant D of 2-propanol is similar to that of 2methoxyethanol have different solvation and therefore different stability after 96 h. As we can see the higher zeta potential values are for 2-methoxyethanol and 2-mercaptoethanol, which leads to greater stability in the dispersion of their particles, because they have a higher load makes them repelled and maintained without addition [24].

On the other hand, the 2-propanol solvent is unstable due to its positive charge, which, as the particles are positive, makes them not interact with the solvent as far as it should and the particles tend to agglomerate, decanting in a shorter time.

\subsection{Nanoparticles supported in carbon nanotubes}

\subsubsection{Atomic absorption spectrophotometry}

Atomic absorption spectrophotometry was performed to identify copper in the obtained solids. They were collected aliquots of solid and brought to digestion for $2 \mathrm{~h}$ in $\mathrm{HCl}_{\text {(conc). }}$. Copper concentrations expressed as percentage weight/weight are given in Table 7 .

Table 7. Percentages for 2-ethoxyethanol/nanoparticles $\mathrm{Cu} / \mathrm{CNT}$ and 2mercaptoethanol / nanoparticles $\mathrm{Cu} / \mathrm{CNT}$.

\begin{tabular}{|c|c|c|}
\hline Solvent & Sample weight & Cu (\%)/CNT \\
\hline 2-ethoxyethanol & 0.0081 & $9.07 \%$ \\
\hline 2-mercaptoethanol & 0.0096 & $4.02 \%$ \\
\hline
\end{tabular}

\subsubsection{Infrared Analysis (FT-IR)}

Table 8 summarizes the most important bands of the spectra of $\mathrm{Cu} /$ nanotube carbon solids with the different solvents.

Table 8. IR absorption characteristic bands for each component of the solids obtained.

\begin{tabular}{|c|c|c|}
\hline Component & Band $\left(\mathrm{cm}^{-1}\right)$ & Band characteristics \\
\hline \multirow{8}{*}{ 2-mercaptoethanol } & 3354.65 & Asymmetric tension $\mathrm{O}-\mathrm{H}$ \\
\hline & 2934.42 & Asymmetric $\mathrm{CH}_{3}$ \\
\hline & 2554.83 & Band S-H \\
\hline & 1637.38 & Moisture \\
\hline & 1418.5 & Torque C-H \\
\hline & 1170.57 & Tension C-O-C \\
\hline & 1059.11 & Asymmetric tension $\mathrm{C}-\mathrm{O}$ \\
\hline & 757.23 & Band C-S \\
\hline \multirow{8}{*}{ 2-ethoxyethanol } & 3390.22 & Asymmetric tension $\mathrm{O}-\mathrm{H}$ \\
\hline & 2971.26 & Asymmetric $\mathrm{CH}_{3}$ \\
\hline & 1648.45 & Moisture \\
\hline & 1451.38 & Torque C-H \\
\hline & 1229.31 & Asymmetric torque $\mathrm{C}-\mathrm{O}$ \\
\hline & 1120.03 & Tension C-O-C \\
\hline & 1064.61 & Asymmetric tension $\mathrm{C}-\mathrm{O}$ \\
\hline & 825.54 & Balancing C-H \\
\hline
\end{tabular}

Figures 14 and 15 show the infrared spectra of metallic solids and pure solvent. By comparing them with the spectra of pure solvents, we can say that there is indeed solvent incorporated into the solid under study.
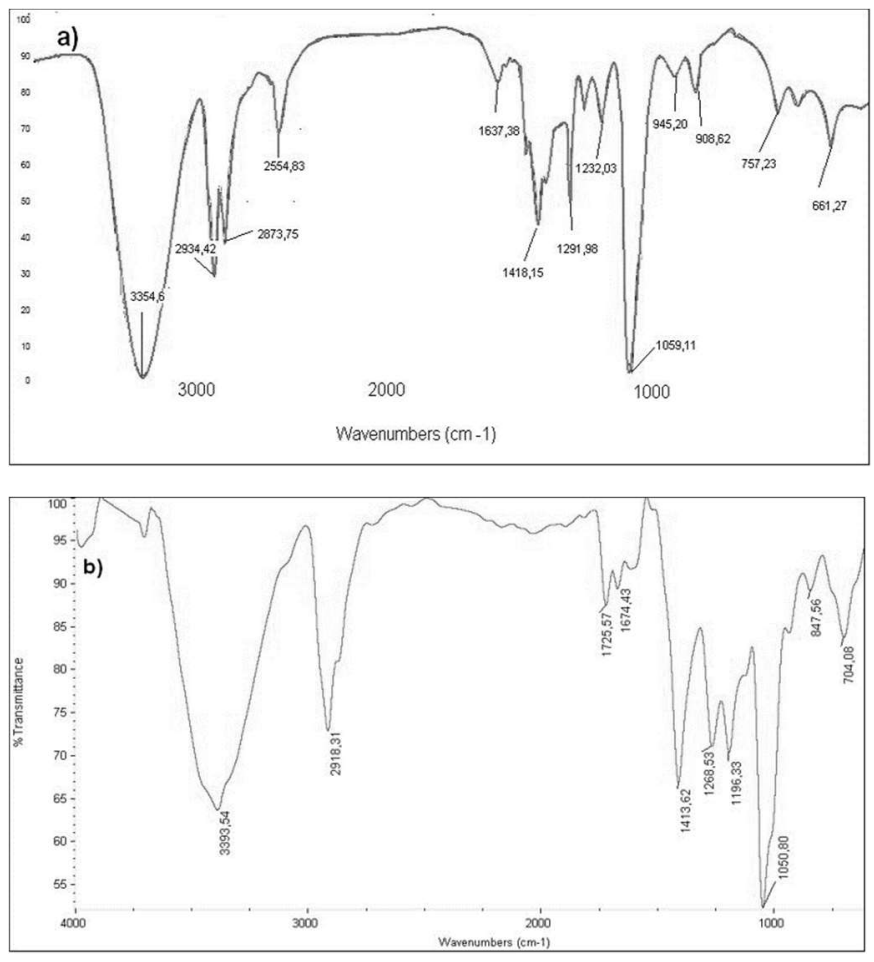

Figure 14. Spectrum in medium IR range a) pure 2-mercaptoethanol; b) from 2-mercaptoethanol/nanoparticles of $\mathrm{Cu} / \mathrm{Carbon}$ nanotubes. 

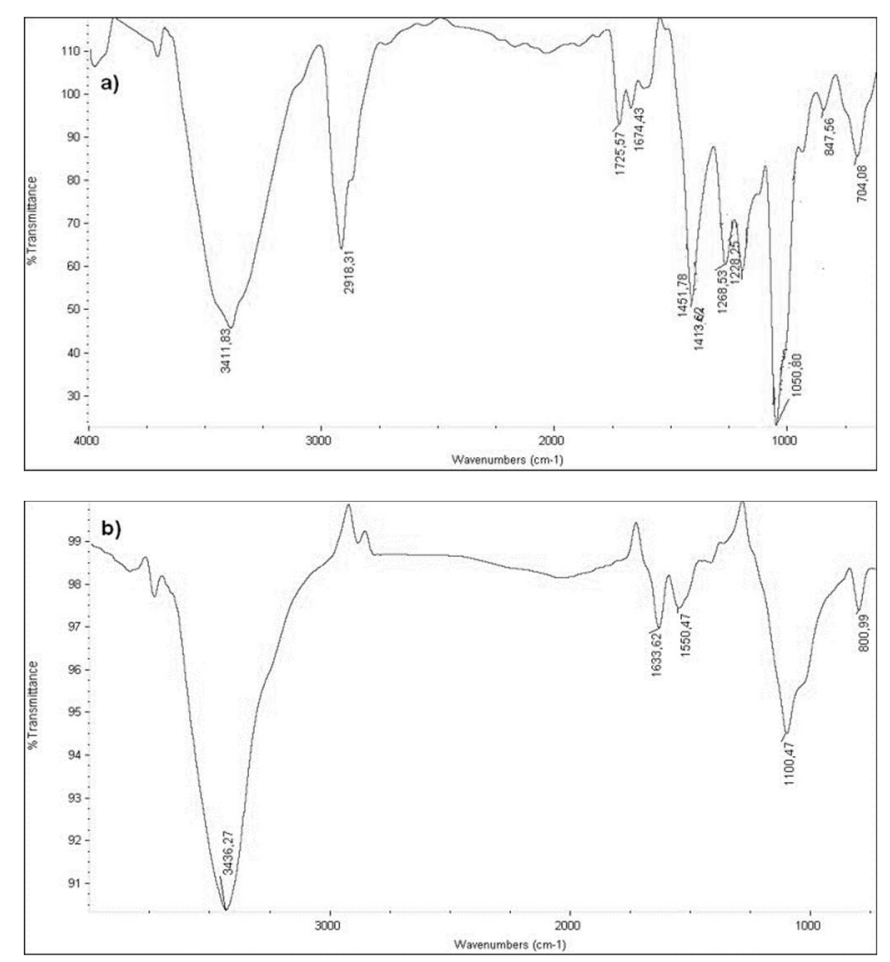

Figure 15. Spectrum in mean IR range a) 2-ethoxyethanol pure; b) From 2ethoxyethanol/Cu nanoparticles/C nanotubes.

Figures 14 and 15 shows that in the spectra for both solids with the solvents used, there is absence of some typical characteristic bands of solvents. This is caused by overlapping bands, as there is also a displacement of these due to the type of reaction presented by the solvent on the surface of the metal, either the interaction with oxygen, carbon or in the case of 2-mercaptoethanol can also be with sulphur, as is the asymmetric band $\mathrm{CH}_{3}$, in the case of the two solids. The appearance of bands such as $\mathrm{H}-\mathrm{O}-\mathrm{H}$ (humidity) may be due to ambient humidity and appears in both spectra for solids.

\subsubsection{Thermogravimetric Analysis (TGA)}

Depending on the interaction of the solvent with the nanoparticles supported in nanotubes vary the amounts of solvent integrated to the solid. The quantity depends on the metal and solvent used [25-28]. Table 9 tells us the decomposition temperatures found for each solid.

Table 9. Thermal events for nanoparticle solids (synthesized in different solvents) supported in carbon nanotubes.

\begin{tabular}{|c|c|c|c|}
\hline Solvent & TD $\left({ }^{\mathbf{}} \mathbf{C}\right)$ & Mass (\%) & Mass loss (\%) \\
\hline \multirow{3}{*}{ 2-ethoxyethanol } & 12.69 & 99.98 & - \\
\cline { 2 - 4 } & 305.13 & - & - \\
\cline { 2 - 4 } & 870.20 & 51.19 & 48.79 \\
\hline \multirow{3}{*}{$\begin{array}{c}\text { 2- } \\
\text { mercaptoethanol }\end{array}$} & 20.07 & 100.1 & - \\
\cline { 2 - 4 } & 289.99 & - & - \\
\hline \multirow{2}{*}{ C Nanotubes } & 941.28 & 45.37 & 54.73 \\
\cline { 2 - 4 } & 22.59 & 100 & - \\
\hline
\end{tabular}

In the thermograms (appendix 1) we can appreciate a thermal event of importance for each of the solvents. In the case of 2-ethoxyethanol an event occurs at $305.13^{\circ} \mathrm{C}$ with a mass loss of $48.79 \%$, this loss occurs as the temperature increases, up to $870.20^{\circ} \mathrm{C}$.

The 2-mercaptoethanol shows a decomposition at $289.99^{\circ} \mathrm{C}$ marked with the greatest mass loss, which increases to $941.28^{\circ} \mathrm{C}$ with a mass loss percentage of $54.93 \%$. Carbon nanotubes, as expected due to their high thermal stability $\left(750^{\circ} \mathrm{C}\right.$ air, $2800^{\circ} \mathrm{C}$ in vacuum) [26-28] do not undergo any transformation, only a loss of $3.54 \%$ that can be moisture, but cannot be said accurately by ignorance of the exact temperature where that small loss occurs. The decomposition of dry materials synthesized in both solvents can be explained in the same way. The nanotubes at their edges contain active carbon atoms, these are linked to the functional groups of solvents generating new properties [29] as shown in figure 16. As time goes on this process is catalyzed with the ambient temperature.

Although nanotubes alone do not suffer transformation at these temperatures or copper (boiling to $1083^{\circ} \mathrm{C}$ ), a hydrophile link interaction can be established between the mercapto group and the nanotubes, which would explain the decrease in their stability by settling 2-mercaptoethanol.

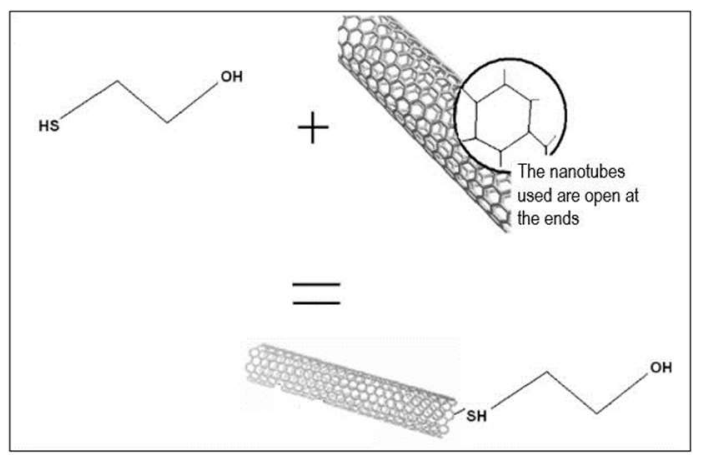

Figure 16. Scheme for solvent reaction and carbon nanotube.

\subsubsection{Transmission electron microscopy}

Figures 17 and 18 shows the arrangement of copper nanoparticles in carbon nanotubes for 2-ethoxyethanol and 2-mercaptoethanol, both $10^{-3} \mathrm{M}$.

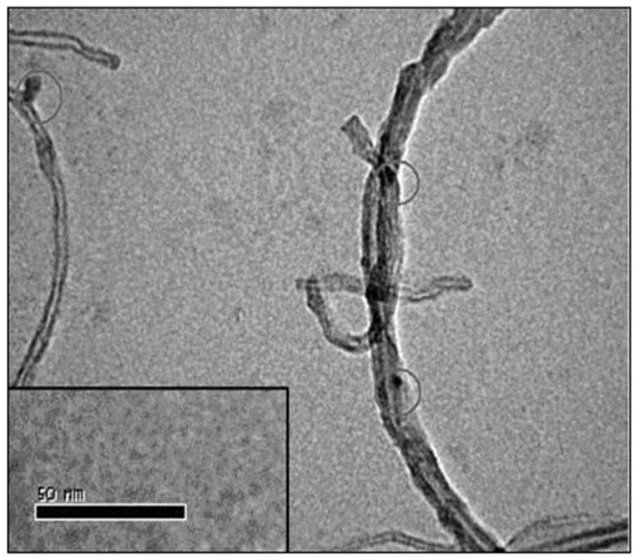

Figure 17. Electronic transmission micrograph (TEM) for colloidal suspension 2-ethoxyethanol/ copper supported in carbon nanotubes. With red are indicated the copper nanoparticles attached to the nanotubes.

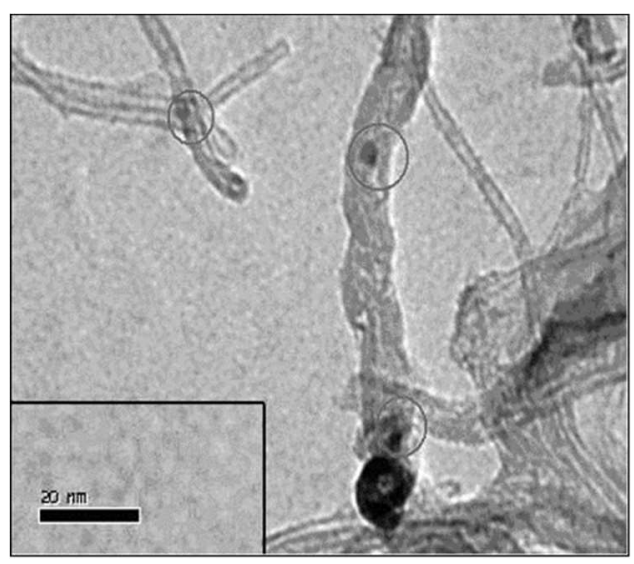

Figure 18. Electronic transmission micrograph (TEM) for colloidal suspension 2-mercaptoethanol / copper supported in nanotubes. With red are indicated the copper nanoparticles attached to the nanotubes. 
Due to the length of the nanotubes $(200 \mathrm{~nm})$ they tend to agglomerate, but this does not prevent the display of interacting particles. It was impossible to obtain electron diffraction from the nanoparticles visualized because they are internal in the nanotubes (multiwall). This makes diffraction impossible. However, in Figures 17 and 18 you can see the copper clusters or agglomerates within the carbon nanotubes (indicated by a circle).

\section{CONCLUSIONS}

The CLD synthesis of copper-solvated atoms gave as highly stable colloid results in 2-propanol, 2-ethoxyethanol and 2-mercaptoethanol. In the case of 2methoxyethanol only the largest part of flocculation particle sizes, the colloid supernatant part is highly stable (more than 2 months).

Spectroscopic studies of colloidal copper suspensions in the UV-Vis region revealed that copper colloids experience continuous absorption in the visible, which increases in the UV region, with a band close to $200 \mathrm{~nm}$, which coincides with the theoretical spectrum.

The study of copper colloid micrographs shows a size distribution between 5.2 and $17.2 \mathrm{~nm}$. This distribution varies with metal concentration and solvent.

By electron diffraction the presence of copper in all the colloids performed is evidenced. By atomic absorption analysis we can quantify the presence of copper in the obtained solid.

FT-IR spectra show the interaction and integration of solvent with copper nanoparticles supported in carbon nanotubes.

The thermogravimetric analysis concludes that the solid obtained undergoes changes by reaction of the nanotubes with the solvent generating adducts with fragments of the solvent.

In the micrographs of the supported solids we can visualize metal particles and carbon nanotubes clearly.

\section{ACKNOWLEDGEMENTS}

The authors would like to thank the financial aid of Fondecyt Grant \# 1080704.

\section{REFERENCES}

1. Haynes WM 2016 Electrical resistivity of pure metals. In CRC Handbook of Chemistry and Physics, 97 th edn, pp 12-42. Boca Raton, FL CRC Press.

2. Haynes WM 2016 Thermal and physical properties of pure metals. In CRC Handbook of Chemistry and Physics, 97 $7^{\text {th }}$ edn,pp.12-218. Boca Raton, FL CRC Press.

3. Subramaniam C, Yamada T, Kobashi K,Sekigushi A. Futaba DN, Yumura M and Hata $\mathrm{K}$. One hundred fold increase in current carrying capacity in a carbon nanotube -copper composite. Nat Commun, 4: 2202 (2013). doi $10.1038 /$ ncomms 3202 .

4. International Copper Study Group.The World Copper Factbook.Portugal: International Copper Study Group, (2014).

5. Sabramaniam C, Yasuda Y, Takeya S, Ata S, Nichisawa A, Fucaba O, Yamada $\mathrm{T}$ and Hata K. Carbon-nanotube copper exhibiting metal-like thermal conductivity and silicon-like thermal expansion for efficient cooling of electrons. Nanoscale 6: 2669-2674, (2014). doi:10.1039/c3nr05290g).

6. Santos-Hernández D, González-García M.B and Costa-García A. MetalNanoparticles Based Electroanalysis. Electroanalysis 14, issue 18: 12251235, (2014). https://doi.org/10.1002/1521-4109(200210)14:18<1225::AIDELAN1225>3.0.CO;2-Z.

7. Cárdenas Galo and Lillo Viviana. Synthesis \& characterization of Co-Ni colloids prepared in nonaqueous solvents. J. Chil. Chem. Soc Vol 52: 11821185, (2007). doi.org/10.4067/S0717-97072007000200014.

8. Blackborow, J. \& Young, D., "Metal Vapour Synthesis in Organometallic Chemistry", Springer- Verlag, Berlín pag. 14, (1979).

9. Aryasomayajula L and Wolter K. Carbon nanotube composites for electronic packaging applications: a review. J. Nanotechnol. 296517: 1-6, (2013). doi:10.1155/2013/296517.

10. Curtin WA and Sheldon BW. CNT-reinforced ceramics and metals. Mater. Today 7: 44-49, (2004). doi:10.1016/S1369-7021(04)00508-5.

11. Neubauer E, Kitzmantel M, Hulman M and Angerer P. Potential and challenges of metal matrix-composites reinforced with carbon nanofibers and carbon nanotubes. Compos. Sci. Technol. 70: 2228-2236, (2010). doi:10.1016/j. compscitech.2010.09.003.
12. Silvestre N. State-of-the-art review on carbon nanotube reinforced metal matrix composites. Int. J. Compos. Mater. 3(A): 28-44, (2013).

13. Azarniya A, Safavi M, Sovizi S, Azarniya A, Chen B, Madaah Hosseini H and Ramakrishna S. Metallurgical challenges in carbon nanotube reinforced metal matrix nanocomposites. Metals 7: 384, (2017). doi:10.3390/met7100384.

14. Azarniya A, Azarniya A, Sovizi S, Hosseini HRM, Varol T, Kawasaki A and Ramakrishna S. Physicomechanical properties of spark plasma sintered carbon nanotube-reinforced metal matrix nanocomposites. Prog. Mater. Sci. 90: 276-324 (2017). doi: 10.1016/j.pmatsci.2017.07.007.

15. Bakir M and Jasiuk I. Novel metal-carbon nanomaterials: a review on covetics. Adv. Mater. Lett. 8: 884-890, (2017). doi:10.5185/amlett. 2017.1598.

16. Jayathilaka WADM, Chinnappan A and Ramakrishna S. A review of properties influencing the conductivity of $\mathrm{CNT} / \mathrm{Cu}$ composites and their applications in wearable/flexible electronics. J. Mater. Chem. C 5: 92099237, (2017). doi:10.1039/ C7TC02965A.

17. Singh A, Ram Prabhu T, Sanjay AR and Koti V. An overview of processing and properties of $\mathrm{Cu} / \mathrm{CNT}$ nano composites. Mater. Today Proc. 4: 38723881, (2017). doi:10.1016/j.matpr.2017.02.286.

18. Janas D and Liszka B. Copper matrix nanocomposites based on carbon nanotubes or graphene. Mater. Chem. Front. 2: 22-35, (2018). doi:10.1039/C7QM00316A.

19. Arnaud C, Lecouturier F, Mesguich D, Ferreira N, Chevallier G, Estournes C, Weibel A and Laurent C. High Strength-high conductivity double-walled carbon nanotube-copper composite wires. Carbon 96: 212-215, (2016). doi:10.1016/j.carbon.2015.09.061.

20. Melendrez M.F, Cárdenas G, Diaz-V J, Cruzat C and Arbiol J. Synthesis and aggregation study of tin nanoparticles and colloids obtained by chemical liquid deposition. Colloid Polym Sci 287: 13-22, (2009). https://doi.org/10.1007/s00396-008-1950-7.

21. Cárdenas G. Chemical reactions at nanometal particles J. Chil. Chem. Soc. $50 \mathrm{~N}^{\circ} 3: 603-612,(2005)$.

22. Tello A, Cárdenas G, Häberle P and Segura R.A. The synthesis of hybrid nanostructures of gold nanoparticles \& carbon nanotubes \& their transformation to solid carbon nanorods. Carbon 46, issue 6: 884-889, (2008). https://doi.org/10.1016/j.carbon.2008.02.024.

23. Turkevich J and Kim G. Palladium: Preparation and Catalytic Properties of Particles of Uniform Size. Science 169, issue 3948:873-879, (1970). doi: 10.1126/science.169.3948.873.

24. Creigthon J. A and Eadon D.G. Ultraviolet-visible absorption spectra of the colloidal metallic elements. J. Chem Soc. Faraday .Trans 87: 3881-3891, (1991). https://doi.org/10.1039/FT9918703881.

25. Cárdenas G, Leon Y, Moreno Y and Peña O. Synthesis and properties of NiSn colloids using different metal ratios by CLD. Collid Polym Sci 284, N6: 644653, (2006). doi: 10.1007/s00396-005-1429-8.

26. Cárdenas G, Oliva R and Gielsing M. Copper colloids from no-aqueous solvents. Part IV Bol. Soc. Chil. Quim 38, (1993).

27. Cárdenas G, Matsuo K and Klabunde K.J .Tin colloids and metal-metal oxide films prepared by chemical liquid deposition. J. Org. Chem 47, 843 (1982).

28. Cárdenas $\mathrm{G}$ and Oliva R. Colloids \& films of $\mathrm{Cu} ; \mathrm{Ag} \& \mathrm{Au}$ from non-aqueous solvent. Part VI Bol. Soc. Chil. Quim.; 38, 301-308 (1993).

29. Sainsbury T, Stolarczyk J and Fritzmaurice D. An experimental \& theoretical study of the self-assembly of gold nanoparticles at the surface of functionalized multiwalled carbon nanotubes. J. Phys. Chem 109: 16325 (2005). 